"This document is the Accepted Manuscript version of a Published Work that appeared in final form in ACS Catalysis, copyright (C) American Chemical Society after peer review and technical editing by the publisher. To access the final edited and published work see https://pubs.acs.org/doi/full/10.1021/acscatal.7b04001."

\title{
Acylative Kinetic Resolution of Alcohols Using a Recyclable Polymer-Supported Isothiourea Catalyst in Batch and Flow
}

\author{
Rifahath Mon Neyyappadath, ${ }^{\dagger}$ Ross Chisholm, ${ }^{\dagger}$ Mark D. Greenhalgh, ${ }^{\dagger}$ Carles Rodríguez-Escrich, ${ }^{\ddagger}$ Mi- \\ quel A. Pericàs, ${ }^{*, \pm, \S}$ Georg Hähner*, ${ }^{*}$ and Andrew D. Smith*, ${ }^{*}$ \\ ${ }^{\dagger}$ EaStCHEM, School of Chemistry, University of St Andrews, North Haugh, St Andrews, KY16 9ST, U.K. \\ *Institute of Chemical Research of Catalonia (ICIQ), The Barcelona Institute of Science and Technology, Av. Països Cata- \\ lans 16, 43007 Tarragona, Spain \\ §Department de Química Inorgànica i Orgànica, Universitat de Barcelona, 08080 Barcelona, Spain \\ kinetic resolution, isothioureas, Lewis base catalysis, polymer-supported catalysts, catalyst recyclability, acyl transfer reac- \\ tions, enantioselective catalysis, continuous flow
}

\begin{abstract}
A polystyrene-supported isothiourea catalyst, based on the homogeneous catalyst HyperBTM, has been prepared and used for the acylative kinetic resolution of secondary alcohols. A wide range of alcohols, including benzylic, allylic and propargylic alcohols, cycloalkanol derivatives and a 1,2-diol, has been resolved using either propionic or isobutyric anhydride with good to excellent selectivity factors obtained (28 examples, $s$ up to 622 ). The catalyst can be recovered and reused by a simple filtration and washing sequence, with no special precautions needed. The recyclability of the catalyst was demonstrated (15 cycles) with no significant loss in either activity or selectivity. The recyclable catalyst was also used for the sequential resolution of 10 different alcohols using different anhydrides with no cross-contamination between cycles. Finally, successful application in a continuous flow process demonstrated the first example of an immobilized Lewis base catalyst used for the kinetic resolution of alcohols in flow.
\end{abstract}

\section{INTRODUCTION}

Catalytic kinetic resolution (KR) processes allow the separation of a racemate into its two enantiomeric forms through the selective reaction of one enantiomer promoted by a chiral catalyst. ${ }^{1}$ The efficiency of a KR is commonly characterized by its selectivity factor $(s)$, defined as the rate constant for the fast reacting enantiomer divided by the rate constant for the slow reacting enantiomer $\left(s=k_{\text {fast }} / k_{\text {slow }}\right){ }^{2}$ KRs with an $s$ of greater than 10 are generally considered to be synthetically useful. The preparation of enantioenriched compounds is of general interest in both academia and industry and as such a tremendous number of KR processes have been devised. Of these methods, the catalytic acylative KR of alcohols is a powerful method to prepare highly enantioenriched alcohols (Scheme 1). ${ }^{3}$ Chiral Lewis base catalysis is most commonly applied for this transformation, with a range of excellent catalysts reported for the KR of many classes of secondary alcohols. A current limitation of this method is that the Lewis base catalyst is rarely recovered from the reaction. This is particularly problematic for methods that require high catalyst loadings ( $>5 \mathrm{~mol} \%$ ) or use expensive catalysts.

A common strategy to facilitate catalyst recovery is catalyst immobilization on an insoluble solid support. ${ }^{4}$ The mild reaction conditions commonly required for organocatalysis makes the use of polymer resins an attractive option due to good chemical stability and efficient swelling in organic solvents. Although many solid-supported organocatalysts have been reported, there are very few examples of application in the acylative KR of alcohols (Scheme 2a). Janda, Anson and Ishihara have used polymer-supported Lewis base catalysts 1-3 for the KR of secondary alcohols. ${ }^{6-8}$ Although good selectivity factors were obtained for cycloalkanols and $N$-protected

Scheme 1. Catalytic Acylative KR of Secondary Alcohols

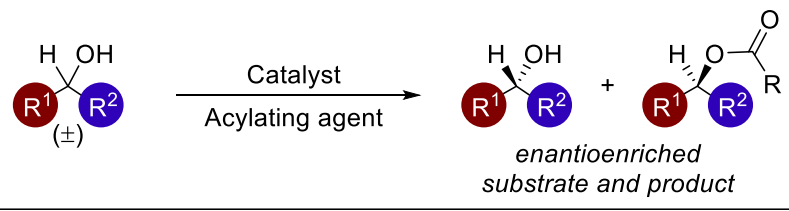

- Enantiodiscrimination requires catalyst recognition and differentiation between $R^{1}$ and $R^{2}$ (steric or electronic bias)

1,2-aminoalcohols, the resolution of benzylic alcohols was inefficient $(s \leq 2)$ and application to other substrate classes was not reported. In all cases the catalysts were recycled up to 5 times, with either none or only minimal catalyst deactivation observed. In an alternative approach, Connon prepared chiral DMAP derivative 4 on the surface of magnetic $\mathrm{Fe}_{3} \mathrm{O}_{4}$ nanoparticles (Scheme 2a). ${ }^{9}$ The catalyst was recycled an impressive 32 times, and used for the resolution of 6 different alcohols. Unfortunately the substrate scope was limited to cycloalkanols, and the selectivity factors obtained were generally low $(s=3-$ 11). ${ }^{10}$ Additionally, there are currently no examples in which immobilized Lewis base catalysts have been applied for the kinetic resolution of alcohols in a continuous flow process. ${ }^{11,12}$

Based on these current limitations, this manuscript reports the development of a recyclable polymer-supported Lewis base catalyst capable of resolving a diverse range of secondary alcohols in both batch and flow. Considering the additional time and cost required to prepare polymer-supported catalysts, we considered catalyst recycling of more than 10 cycles necessary to show acceptable recyclability. In addition, the ideal catalyst would be capable of sequentially resolving different

Scheme 2. Solid-Supported Lewis Base Catalysts used for KR of Alcohols 
a) Previous Examples

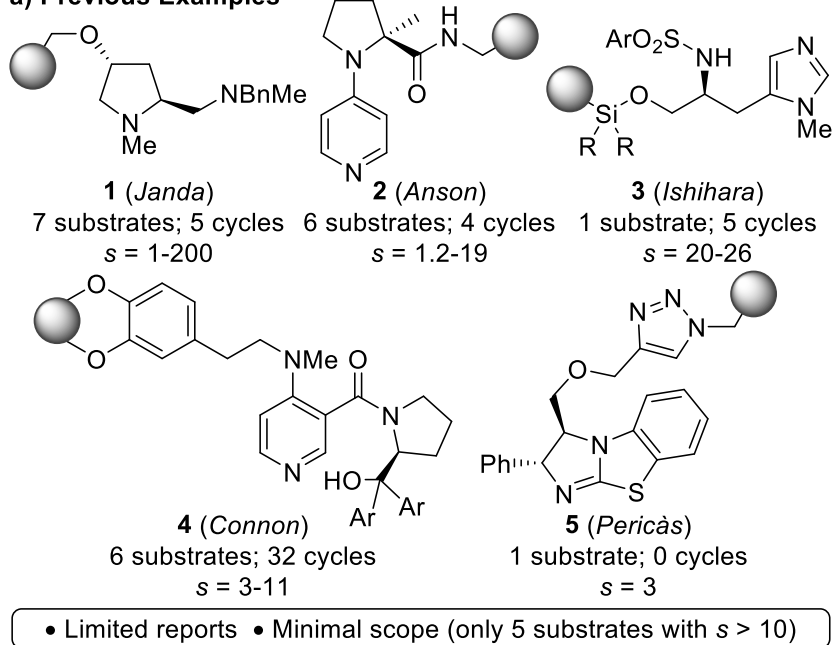

b) This Work

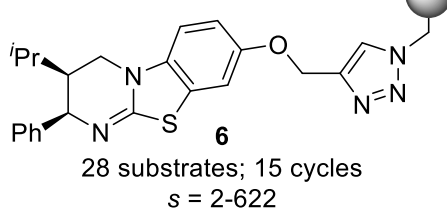

- Benzylic, allylic and propargylic alcohols, cycloalkanols and diols - Recycled with different alcohols \& anhydrides without loss in activity - Applied in continuous flow

alcohols using different acylating agents without loss in activity or cross-contamination of products.

Isothioureas have been successfully applied as Lewis base catalysts for a range of enantioselective processes,${ }^{13}$ building upon Birman's initial application as enantioselective acylation catalysts. ${ }^{14}$ They have proven useful in the KR of a wide range of secondary alcohols including benzylic, allylic and propargylic alcohols, cycloalkanols and $\alpha$-hydroxy alkanoates. ${ }^{14-16} \mathrm{Re}$ cently Pericàs reported the synthesis of the first polymer-supported isothiourea $\mathbf{5}$, and applied it as a catalyst for formal $[4+2],[2+2]$ and $[8+2]$ cycloaddition reactions (Scheme 2a). ${ }^{17}$ A range of heterocyclic products were obtained in good yields and with excellent diastereo- and enantiocontrol, with the catalyst used in both batch and continuous flow processes. It was noted however that the catalyst was inefficient for the KR of $( \pm)$-1-phenylethanol, with only a low conversion and minimal selectivity obtained after an extended reaction time. ${ }^{17 a}$ This is in contrast to the homogenous variant of this catalyst, benzotetramisole (BTM), which has been successfully applied for this transformation. ${ }^{14}$

An alternative isothiourea catalyst, HyperBTM, ${ }^{18}$ developed in our laboratory has also been applied for the KR of benzylic, allylic and propargylic alcohols. ${ }^{16}$ Herein we describe the synthesis of a polystyrene-supported variant of the isothiourea catalyst HyperBTM 6, and demonstrate its application as a catalyst for the KR of a range of secondary alcohols (Scheme 2b). The durability of the catalyst is demonstrated in recycling studies using either the same alcohol and anhydride or different alcohols and anhydrides, and through application in a continuous flow procedure.

\section{RESULTS AND DISCUSSION}

Synthesis of Polystyrene-Supported HyperBTM. The synthesis of a polystyrene-supported variant of HyperBTM $\mathbf{6}$, began with the coupling of the $\mathrm{HCl}$ salt of $(R)-2-((R)$-amino(phenyl)methyl)-3-methylbutan-1-ol $7^{19}$ with 2-chloro-6-methoxybenzo[d] thiazole 8 followed by in situ cyclization to give 8MeO-HyperBTM 9 in 71\% yield (Scheme 3). Demethylation, followed by propargylation gave alkyne-substituted HyperBTM derivative 11 (68\% over 2 steps), which could be attached to a Merrifield resin-derived azidomethyl polystyrene support by a $\mathrm{Cu}$-catalyzed azide-alkyne cycloaddition reaction. ${ }^{20}$ The nitrogen content of polymer $\mathbf{6}$, determined by elemental analysis, was used to calculate the functionalization of $6(0.88 \mathrm{mmol}$ $\left.\mathrm{g}^{-1}\right){ }^{21,22}$ This value of functionalization was used to calculate the catalyst loading in subsequent KRs.

\section{Scheme 3. Synthesis of Polystyrene-Supported HyperBTM}

6

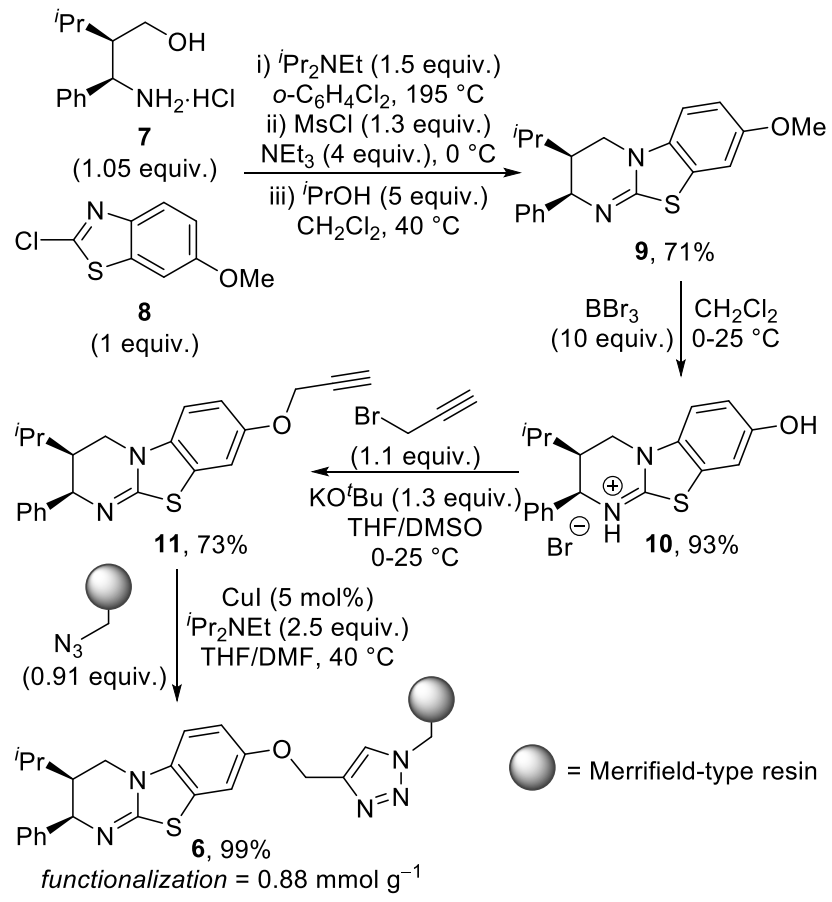

Reaction Optimization. Initial studies focused on the KR of a model secondary alcohol, $( \pm)$-1-(naphthalen-2-yl)ethan-1-ol 12, using polystyrene-supported HyperBTM 6 ( $1 \mathrm{~mol} \%)$ as catalyst (Table 1). Using propionic anhydride as acyl donor $(0.55$ equiv.) in chloroform at room temperature resulted in an efficient $\mathrm{KR}$ of $( \pm)-\mathbf{1 2}$, giving $51 \%$ conversion within $4 \mathrm{~h}$ and a selectivity factor of 44 (entry 1 ). ${ }^{23}$ Increasing the steric bulk of the anhydride, from propionic to isobutyric, gave an improved selectivity factor of 79 (entry 2). As the choice of solvent is known to have a significant effect on the swelling properties of polymer supports, ${ }^{4 \mathrm{c}}$ a range of solvents were tested for applicability in the developed KR process (entries 2-7). With the exception of acetonitrile (entry 3 ) all other solvents provided ideal conversion of $\sim 50 \%$, with chloroform and toluene giving the highest selectivity factors (79 and 69 respectively, entries 2 and 7). Notably, industrially-preferable solvents such as EtOAc also gave good conversion and selectivity $(s=42),{ }^{24}$ however chloroform and toluene were chosen for further optimization. Lowering the reaction temperature to $0{ }^{\circ} \mathrm{C}$ further improved selectivity (entries 8-9), with 
Table 1. KR of $( \pm)-12$ using Polystyrene-Supported HyperBTM 6: Optimization ${ }^{a}$

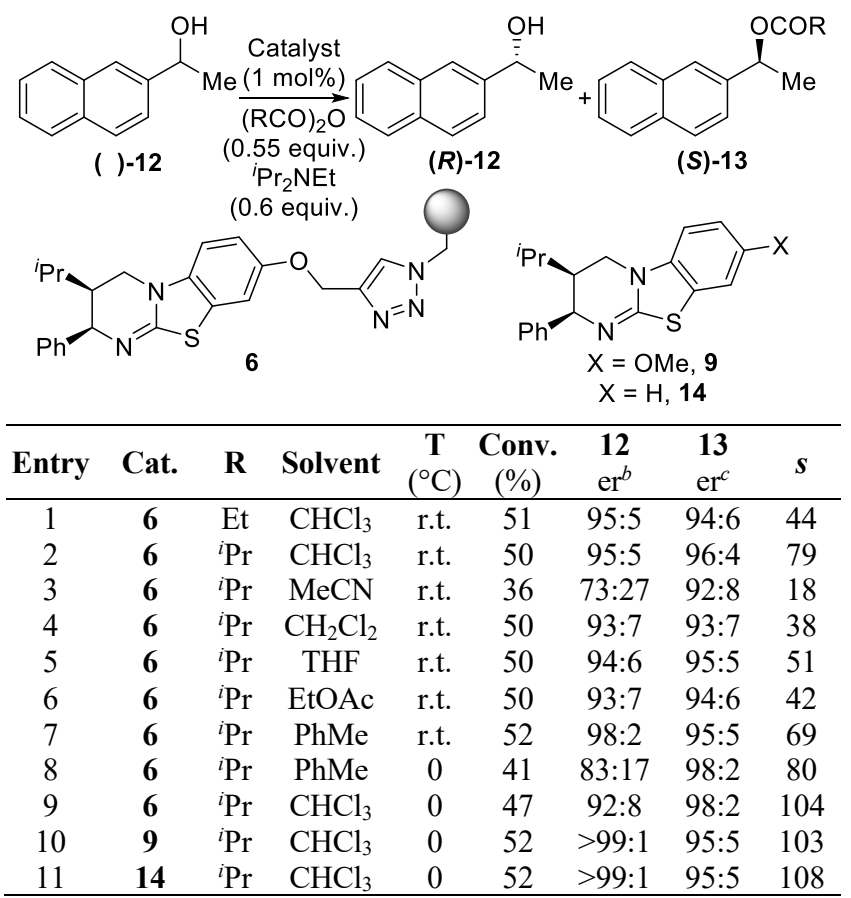

${ }^{a}$ Reaction conditions: alcohol $(0.2 \mathrm{mmol})$, Catalyst 6,9 or $14(1 \mathrm{~mol} \%)$, ${ }^{i} \operatorname{Pr}_{2} \mathrm{NEt}$ ( 0.6 equiv.), anhydride ( 0.55 equiv.), solvent $(0.2 \mathrm{M}), 4-7 \mathrm{~h}$. Conversion and er determined by chiral HPLC analysis. Selectivity factors $(s)$ calculated using er of $\mathbf{1 2}$ and reaction conversion (see ref. 2). ${ }^{b} R: S .{ }^{c} S: R$.

chloroform out-performing toluene in terms of both reaction conversion and selectivity factor (conversion $=47 \%, s=105$ ). To provide a direct comparison with homogenous isothiourea catalysts, the KR of $( \pm)$-12 using 8-OMe-HyperBTM 9 and HyperBTM 14 was performed under analogous reaction conditions (entries 10-11). Both homogenous catalysts gave slightly higher conversion $(52 \%)$, but essentially equal selectivity $(s=103$ 108 ), suggesting that the 8-alkoxy substituent and polystyrene support of $\mathbf{6}$ do not have detrimental effects on catalyst selectivity.

Catalyst Recyclability. Encouraged by the excellent activity and selectivity obtained using polystyrene-supported HyperBTM 6, the recyclability and robustness of the catalyst was investigated. The catalyst could be recovered by filtration, followed by washing sequentially with $\mathrm{CHCl}_{3}, \mathrm{MeOH}$ and THF and finally drying under high vacuum for $2 \mathrm{~h}$. Using the KR of $( \pm)-12$ in chloroform at $0{ }^{\circ} \mathrm{C}$ for $7 \mathrm{~h}$ as standard, the catalyst was recovered and reused in 15 consecutive KRs (Figure 1). Reaction conversion remained very consistent over all 15 cycles (47 $\pm 3 \%$ ) indicating the activity of the catalyst remained unaltered, and corresponding to a combined turnover number (TON) of over 700 . The selectivity factor was more variable $(90 \pm 12)$, however there was no overall loss in selectivity, with the selectivity factor for the $15^{\text {th }}$ cycle $(s=95)$ essentially equal to that obtained for the $1^{\text {st }}$ cycle $(s=89)$. The variability observed in $s$ may result from a combination of slight inconsistencies in catalyst regeneration after each cycle, and the inherent error present when calculating selectivity factors for highly selective KRs. ${ }^{1,2}$
Figure 1. Recycling of 6 for the KR of $( \pm)-12$
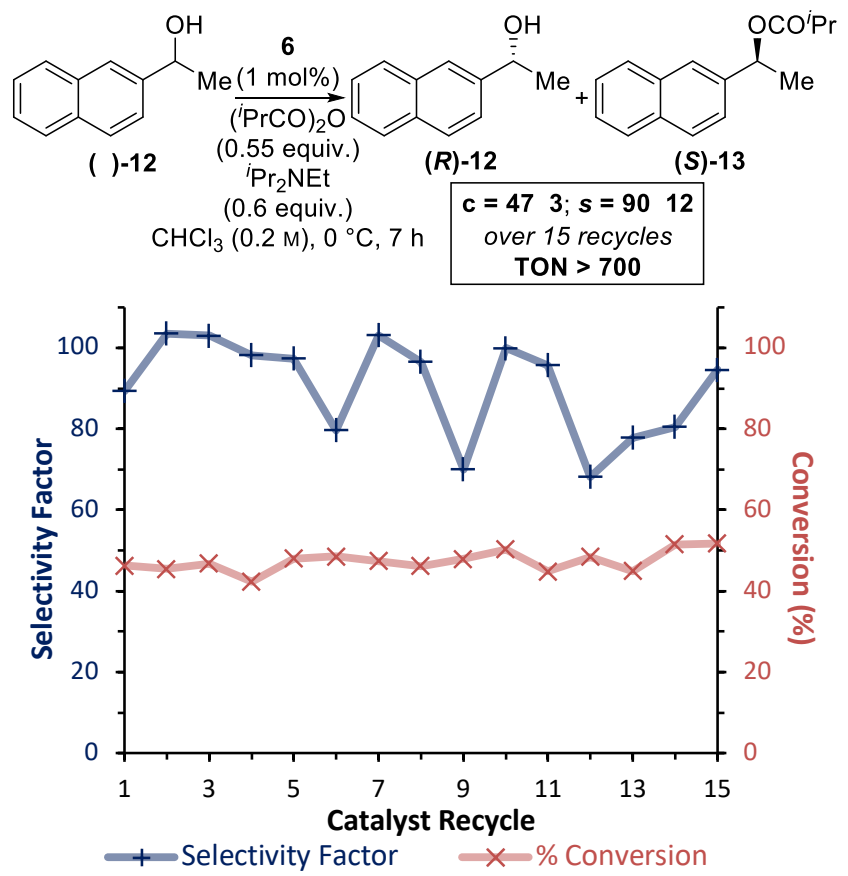

Substrate Scope and Limitations. The limited range of secondary alcohols previously resolved using polymer-supported Lewis base catalysts inspired us to probe the scope of the current method. In particular, different classes of structurally-diverse secondary alcohols were targeted. The KR of secondary benzylic alcohols is considered a 'benchmark' reaction for Lewis base catalyzed acylative KR, however previous polymersupported variants have proved ineffective for this substrate class (highest reported $s=3$ ). The KR of benzylic alcohols bearing various substituents at the $\alpha$-position and on the aromatic ring was therefore investigated (Table 2). Applying the previously optimized conditions, the KR of $( \pm)$-1-phenylethanol 15 was achieved with good conversion and selectivity $(s=46)$. Increasing the steric bulk of the $\alpha$-alkyl substituent $(\mathbf{1 5} \rightarrow \mathbf{1 8})$ resulted in improved selectivity, although increased catalyst loading $(5 \mathrm{~mol} \%)$ and reaction time $(30 \mathrm{~h})$ were required for good conversion with $t$-Bu-substituted benzylic alcohol 18. Although $\alpha$-trifluoromethyl benzyl alcohol 19 was resolved with only low selectivity, the $\alpha$-chloromethyl-substituted analogue $\mathbf{2 0}$ was resolved with a good $s$ of 31 . The introduction of both electrondonating $(\mathrm{OMe}, \mathbf{2 1})$ and withdrawing substituents $\left(\mathrm{F}, \mathrm{CF}_{3}, \mathbf{2 2}\right.$ and 23) on the aromatic ring was tolerated, however lower selectivity factors were obtained for substrates $\mathbf{2 2}$ and $\mathbf{2 3}$ bearing electron-withdrawing groups. This is in keeping with previous reports of isothiourea-catalyzed KR of alcohols and is consistent with a $\pi$-cation interaction between the benzylic alcohol and the acyl isothiouronium playing a significant role in substrate recognition. ${ }^{15 g}$ ortho-Substitution on the aromatic ring was also tolerated, with substrates 24-26 resolved with good selectivity $(s=14-77)$, although the KR of sterically-hindered 26 did require resolution at room temperature to obtain good conversion. An exceptionally high selectivity factor of $>600$ was obtained for the resolution of 2-naphthyl derivative 27. The KR of heteroaromatic alcohols was also briefly studied. 2Thienyl alcohol 28 was resolved with good selectivity $(s=25)$, however 2-pyridyl analogue $\mathbf{2 9}$ was resolved with very poor selectivity $(s=2)$, highlighting a current limitation. 
Table 2. KR of Benzylic Alcohols

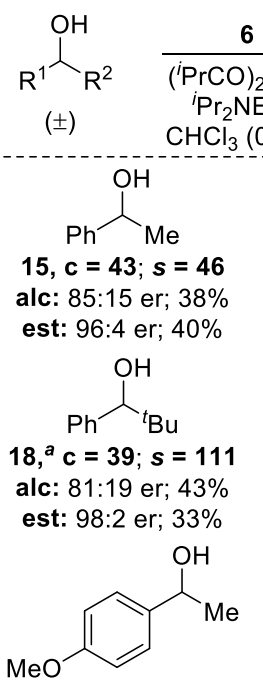

$21, c=39 ; s=31$

alc: $79: 21$ er; $52 \%$ est: $95: 5$ er; $30 \%$<smiles>COc1ccc(OC)c(C(C)O)c1</smiles>

24, $c=42 ; s=14$ alc: $78: 22 \mathrm{er} ; 48 \%$ est: $89: 11$ er; $40 \%$<smiles>CCC(O)c1ccc2ccccc2c1</smiles>

$27, c=45 ; s=622$ alc: $91: 9$ er; $52 \%$ est: $>99: 1$ er; $42 \%$

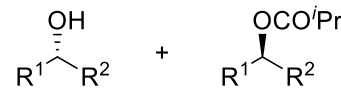

$\mathrm{M}), 0^{\circ} \mathrm{C}, 7 \mathrm{~h}$

$$
\overbrace{E t}^{\mathrm{OH}}
$$

16, $c=47 ; s=65$

alc: $92: 8$ er; $37 \%$

est: $96: 4$ er; $36 \%$<smiles>OC(c1ccccc1)C(F)(F)F</smiles>

$19, \mathrm{c}=48 ; s=4$

alc: $72: 28$ er; $45 \%$

est: $73: 27$ er; $42 \%$<smiles>CC(O)c1ccc(F)cc1</smiles>

$22, c=45 ; s=22$

alc: $83: 17$ er; $47 \%$

est: $92: 8$ er; $36 \%$<smiles>CC(O)c1cccc2ccccc12</smiles>

25, $c=47 ; s=41$ alc: $90: 10 \mathrm{er} ; 48 \%$ est: $94: 6$ er; $43 \%$

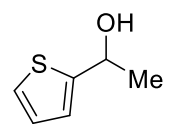

28, $c=49 ; s=25$

alc: $90: 10$ er; $41 \%$ est: $91: 9$ er; $39 \%$

$$
\text { 17, } \mathrm{c}=\mathbf{4 0} ; \mathbf{s}=\mathbf{8 0}
$$

alc: $82: 18 \mathrm{er} ; 45 \%$

est: $98: 2$ er; $29 \%$

$\mathrm{OH}$<smiles>ClCC(CCl)CC(c1ccccc1)c1ccccc1</smiles>

20, $c=51 ; s=31$

alc: $93: 7 \mathrm{er} ; 38 \%$

est: $92: 8 \mathrm{er} ; 44 \%$<smiles>CC(O)c1ccc(C(F)(F)F)cc1</smiles>

23, $c=53 ; s=15$ alc: $91: 9 \mathrm{er} ; 39 \%$

est: $86: 14$ er; $46 \%$

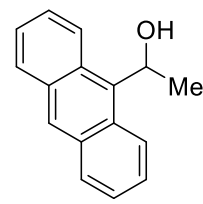

$26,{ }^{b} \mathrm{c}=44 ; s=77$ alc: $88: 12$ er; $54 \%$ est: $97: 3 \mathrm{er} ; 40 \%$<smiles>CC(O)c1ccccn1</smiles>

29, $\mathrm{c}=30 ; \mathrm{s}=\mathbf{2}$ alc: $56: 44$ er; $54 \%$ est: $63: 37$ er; $21 \%$
Conversion and er determined by chiral HPLC analysis. Selectivity factors $(s)$ calculated using alcohol er and reaction conversion (see ref. 2). Alcohol er given as $R: S$, ester er given $S: R .{ }^{a} 5 \mathrm{~mol} \%$ 6, r.t., 30 h. ${ }^{b}$ r.t.

The substrate scope was extended to allylic and propargylic alcohols, with $\pi$-cation interactions between the substrate and catalyst again expected to enable enantiodiscrimination (Table 3). Cinnamyl alcohol derivative $\mathbf{3 0}$ underwent effective $\mathrm{KR}(s=$ $17) .^{23}$ The resolution of a potentially-challenging aryl-alkenyl alcohol 31, where the catalyst would be required to differentiate between two $\pi$-systems, was also attempted. ${ }^{16 \mathrm{~b}}$ An efficient KR was still achieved $(s=25)$, with the enantiodiscrimination obtained consistent with the naphthalene unit acting as the dominant recognition motif in this case. ${ }^{23,16 \mathrm{~b}}$ Propargylic alcohols 32 and 33 were also resolved with good selectivity $(s=23-26) .^{23}$ The resolution of an aryl-alkynyl alcohol 34 was also attempted to again probe catalyst differentiation between two $\pi$-systems. In this example very low selectivity was obtained $(s=3)$, consistent with the respective $\pi$-cation interactions between the phenyl and acetylene units and an acyl-isothiouronium intermediate being comparable in magnitude. ${ }^{23}$

The KR of cycloalkanols was next studied (Table 4). Previous isothiourea-catalyzed methods have demonstrated the need for an adjacent substituent (generally aryl) which can interact with the catalyst to provide effective enantiodiscrimination. ${ }^{15 \mathrm{~b}, \mathrm{c}} \mathrm{With}$ this pre-requisite in mind, the resolutions of trans- and cis-phenylcyclohexanol $\mathbf{3 5}$ and $\mathbf{3 7}$ were first studied.
Table 3. KR of Allylic and Propargylic Alcohols

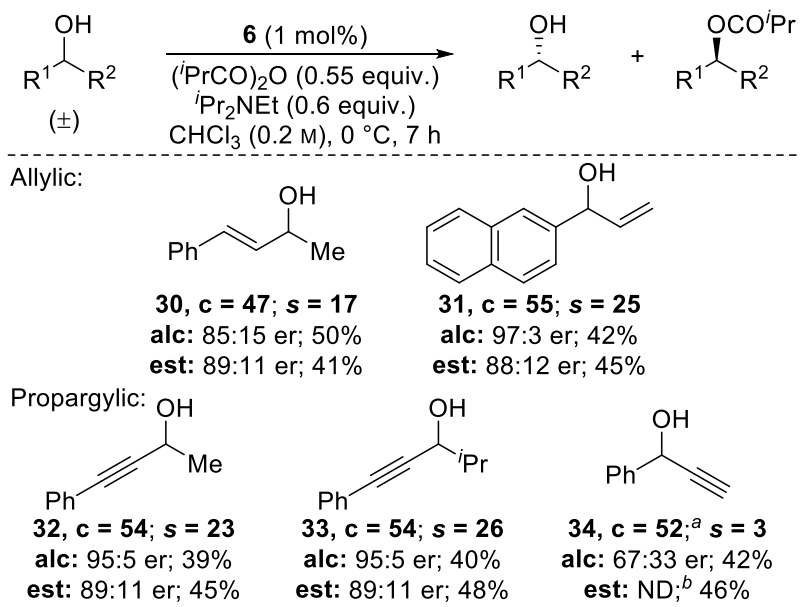

Conversion and er determined by chiral HPLC analysis. Selectivity factors $(s)$ calculated using alcohol er and reaction conversion (see ref. 2). Alcohol er given as $R: S$, ester er given $S: R .{ }^{a}$ Conversion determined by ${ }^{1} \mathrm{H}$ NMR spectroscopy. ${ }^{b}$ er could not be determined by chiral HPLC or GC.

Consistent with the work of Birman, ${ }^{15 \mathrm{~b}}$ propionic anhydride gave improved conversion and selectivity factors relative to isobutyric anhydride. ${ }^{22}$ Both diastereoisomers underwent effective $\mathrm{KR}$, with trans-phenylcyclohexanol 35 giving the higher selectivity factor $(s=51) .{ }^{25}$ Indole-substituted cyclohexanol 39 was also efficiently resolved $(s=51)$, whilst

Table 4. KR of Cycloalkanol derivatives

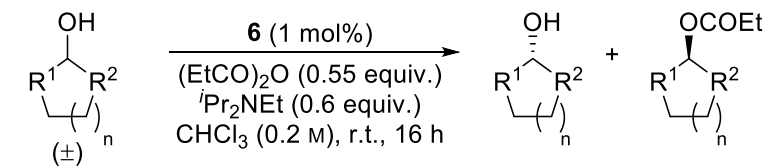

conv

Conversion and er determined by chiral HPLC analysis. Selectivity factors $(s)$ calculated using alcohol er and reaction conversion (see ref. 2). ${ }^{a}$ $\left({ }^{i} \mathrm{PrCO}\right)_{2} \mathrm{O}(0.55$ equiv. $)$ used in place of $(\mathrm{EtCO})_{2} \mathrm{O} .{ }^{b} 7 \mathrm{~h}$ 
reducing the ring size to trans-phenylcyclopentanol 41 was also well tolerated $(s=72)$. Interestingly, for the resolution of transphenylcyclopentanol 41, isobutyric anhydride proved the optimal acyl donor, with propionic anhydride providing significantly lower selectivity $(s=36) .{ }^{22}$ An acyclic analogue, homobenzylic alcohol 43, was resolved with low selectivity $(s=7)$, suggesting that the conformational rigidity of the cycloalkanol derivatives may be beneficial for effective recognition by the catalyst. $^{15 \mathrm{~g}}$

The KR of a 1,2-diol, ( \pm )-1,2-diphenylethane-1,2-diol 45, was next investigated (Table 5). Under standard conditions a mixture of diol $(\boldsymbol{S}, \boldsymbol{S})-\mathbf{4 5},{ }^{26}$ monoester $(\boldsymbol{R}, \boldsymbol{R})-\mathbf{4 6}$ and diester $(\boldsymbol{R}, \boldsymbol{R})-\mathbf{4 7}$ was obtained (entry 1$)$. The selectivity factor for the KR of diol $( \pm)-\mathbf{4 5}$ was determined to be $20,{ }^{27}$ however, diester $(\boldsymbol{R}, \boldsymbol{R})-\mathbf{4 7}$ was obtained in highly enantioenriched form (99:1), indicating an amplification in enantiopurity through operation of a second $\mathrm{KR}$ of monoester 46. A control $\mathrm{KR}$ using racemic monoester $( \pm)-46$ revealed this second KR proceeds with very high selectivity (conversion $=47 \%, s=108$ ) and the same sense of enantiodiscrimination, ${ }^{22}$ consistent with the observed amplification in enantiopurity of diester $(\boldsymbol{R}, \boldsymbol{R})-\mathbf{4 7}$. This effect was exploited for the KR of diol $( \pm)-45$ by using 1.5 equiv. of anhydride to increase reaction conversion and allow the isolation of highly enantioenriched diol $(\boldsymbol{S}, \boldsymbol{S})-\mathbf{4 5}$ and diester $(\boldsymbol{R}, \boldsymbol{R})-\mathbf{4 7}$ (both $>99: 1$ er) (entry 2). A similar effect was recently reported in the isothiourea-catalysed KR of 1,3 -diols, ${ }^{28 a}$ however, to the best of our knowledge, this is the first example of an isothiourea-catalyzed KR of a 1,2-diol. ${ }^{28}$

Table 5. KR of a 1,2-Diol

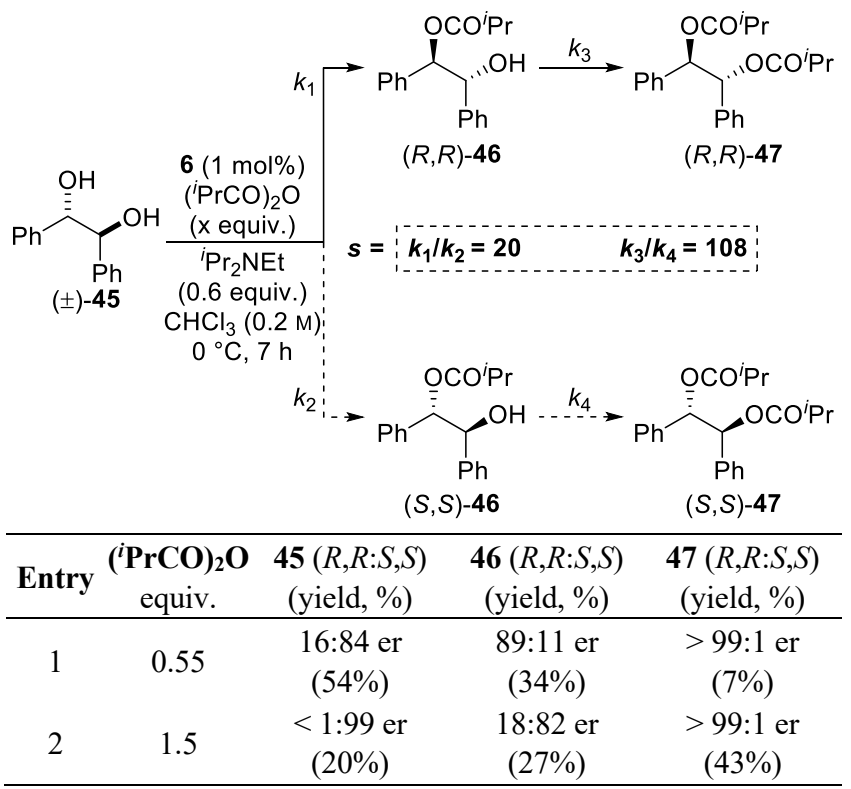

Conversion and er determined by chiral HPLC analysis. Selectivity factor $(s)$ calculated using alcohol er and reaction conversion (see ref. 2).

The developed method was next applied to the enantioselective synthesis of the $(S)$-enantiomer of $\beta$-blocker pronethalol $(S)-49$ (Scheme 5). ${ }^{29}$ The KR of 1,2-azidoalcohol 48 was achieved with an excellent $s$ of 96 , allowing recovery of $(S)-48$ in $42 \%$ yield and $>99: 1$ er. Subsequent reduction of the azide and in situ reductive amination of acetone provided $(S)$-pronethalol in $81 \%$ yield. The excellent selectivity factor obtained for the KR of 1,2-azidoalcohol 48 indicates this method could be successfully applied more generally to the synthesis of enantiopure 1,2aminoalcohols.
Scheme 5. KR of 1,2-Azidoalcohol 48 and Synthesis of $(S)$ Pronethalol (S)-49

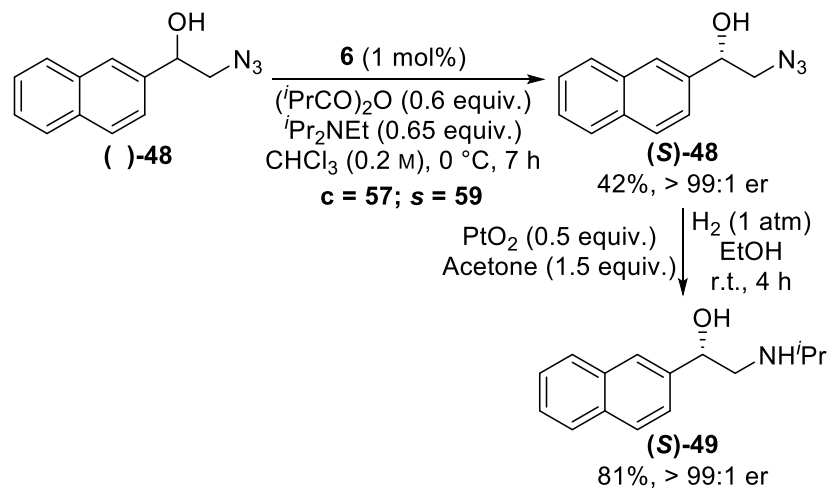

Conversion and er determined by chiral HPLC analysis. Selectivity factor $(s)$ calculated using alcohol er and reaction conversion (see ref. 2).

Having demonstrated the KR of a range of classes of secondary alcohols, the recyclability of polystyrene-supported HyperBTM 6 was finally tested for the sequential KR of 10 different alcohols (Table 6). Significantly either propionic or isobutyric anhydride could be used without any cross-contamination between cycles. Generally, slightly lower conversions and selectivity factors were obtained compared to the results obtained using fresh catalyst (data shown italicized in square brackets), however there was no overall drop in activity over the course of the cycling, with the final cycle (entry 10) providing a similar conversion and identical selectivity factor to that obtained using fresh catalyst.

Application in Continuous Flow. The exceptional recyclability and versatility of polystyrene-supported catalyst $\mathbf{6}$ prompted application in a continuous flow set-up. Polystyrene-supported catalyst 6 (600 mg, $0.54 \mathrm{mmol})$ was swollen in $\mathrm{CHCl}_{3}$ in a sizeadjustable, medium pressure borosilicate glass column to create a packed bed reactor. A cooling jacket was attached to maintain a constant reaction temperature and solutions of racemic alcohol $(0.4 \mathrm{M})$ and a mixture of anhydride $(0.24 \mathrm{M})$ and base $(0.26$ M) in $\mathrm{CHCl}_{3}$ were passed through the vertical packed bed reactor using a syringe pump. Improved selectivity factors were obtained at $0{ }^{\circ} \mathrm{C}$ relative to room temperature; and a combined flow rate of $0.1 \mathrm{~mL} \mathrm{~min}^{-1}$, providing a residence time of $30 \mathrm{~min}$, was found to be optimal to achieve $>50 \%$ conversion (Scheme $6)$. The KR of 1-phenylethanol ( \pm )-15 using isobutyric anhydride was highly reproducible, with $54-56 \%$ conversion and $s$ of 27-30 obtained in five consecutive $4 \mathrm{mmol}$ scale reactions. ${ }^{22}$ The robustness of the same packed bed reactor was exemplified by the KR of $28.8 \mathrm{mmol}$ of 1-phenylethanol $( \pm)-\mathbf{1 5}$ over a $24 \mathrm{~h}$ period in a continuous flow process (Scheme 6). A conversion of $55 \%$ and $s$ of 28 were obtained, with $(R)$-1-phenylethanol $(\boldsymbol{R})-\mathbf{1 5}$ recovered in 40\% yield $(11.5 \mathrm{mmol})$ and $97: 3 \mathrm{er}$.

To further demonstrate the applicability of the continuous flow process, the same packed bed reactor that had been used for optimization studies and the resolution of 1-phenylethanol was then used for sequential KRs using 9 different alcohol/anhydride combinations (Table 7). Each KR was carried out on a 4 mmol scale, with the packed bed reactor simply flushed with $\mathrm{CHCl}_{3}$ or $\mathrm{CHCl}_{3} / \mathrm{MeOH}(9: 1)$ between reactions. ${ }^{30}$ A selection of benzylic, allylic, propargylic and cycloalkanol derivatives were resolved with optimal conversion (49-63\%) and good to excellent selectivity factors $(s=11-175)$, allowing isolation of the enantioenriched alcohol in 
Table 6. Recycling of Polystyrene-Supported HyperBTM 6 for the KR 10 Different Substrates

(1)

Conversion and er determined by chiral HPLC analysis. Selectivity factors $(s)$ calculated using alcohol er and reaction conversion (see ref. 2). ${ }^{a}$ Conversion and $s$ data for resolutions using fresh catalyst (from Tables 1-4) shown in italics in square brackets. ${ }^{b}$ r.t., $16 \mathrm{~h}$.

92:8-99:1 er in each case. Significantly, the use of different alcohols and anhydrides with the same packed bed reactor gave spectroscopically-pure products in each case with no evidence of cross-contamination or catalyst deactivation observed. Remarkably, all the flow experiments described in this paper, including optimization and repeat reactions, were performed with the same sample of polystyrene-supported catalyst $\mathbf{6}$, resulting in a total operation time in excess of $100 \mathrm{~h}$.
Scheme 6. KR of 1-Phenylethanol in Continuous Flow

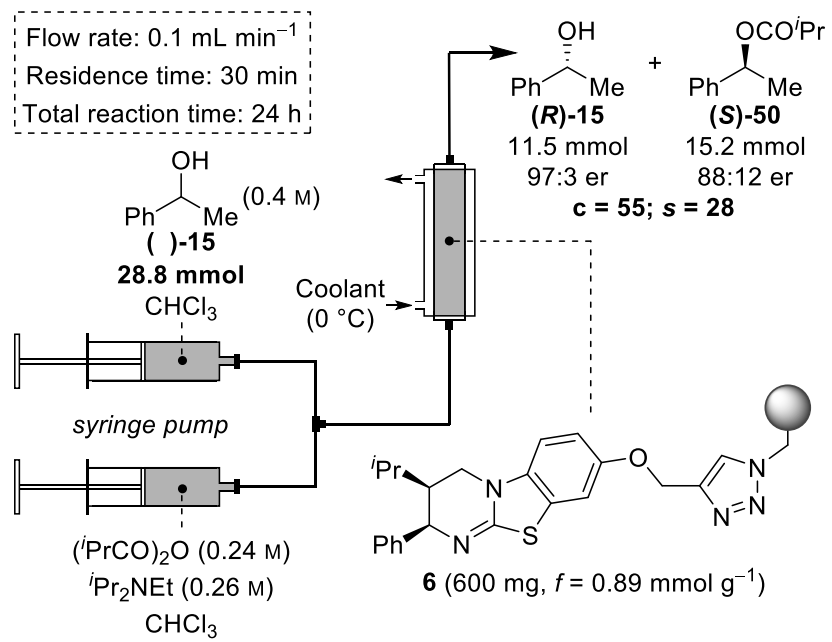

Conversion and er determined by chiral HPLC analysis. Selectivity factor $(s)$ calculated using alcohol er and reaction conversion (see ref. 2).

Table 7. Continuous Flow KR of Different Alcohols using the Same Packed Bed Reactor

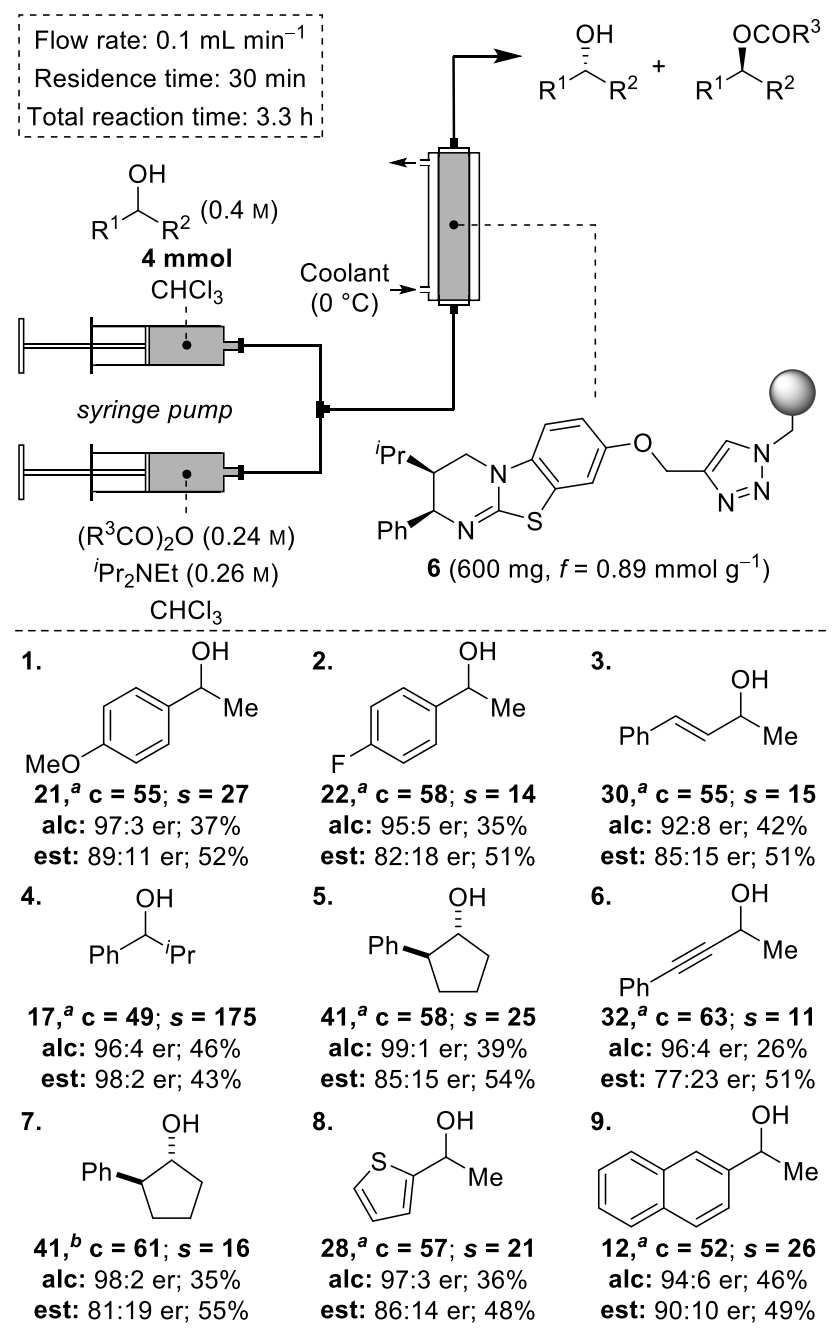

Conversion and er determined by chiral HPLC analysis. Selectivity factor $(s)$ calculated using alcohol er and reaction conversion (see ref. 2). ${ }^{a}$ $\left({ }^{i} \mathrm{PrCO}\right)_{2} \mathrm{O}$ used. ${ }^{b}(\mathrm{EtCO})_{2} \mathrm{O}$ used. 


\section{CONCLUSION}

The synthesis of polystyrene-supported isothiourea catalyst 6 was achieved in four steps from $(R)-2-((R)$-amino(phenyl)methyl)-3-methylbutan-1-ol in $48 \%$ overall yield. The KR of a range of secondary alcohols was demonstrated using $\mathbf{6}$ as catalyst ( $1 \mathrm{~mol} \%)$, with the substrate scope including benzylic, allylic and propargylic alcohols, cycloalkanol derivatives and a 1,2-diol (28 examples). The majority of examples were resolved with good to excellent selectivity factors ( $s$ up to $>600$ ), showing this process has a broad substrate scope, well beyond that of other solid-supported Lewis base catalysts reported to date. The recyclability of the catalyst was demonstrated for the resolution of a single alcohol (15 cycles), and for the sequential resolution of 10 different alcohols using different anhydrides, with no significant loss in activity or selectivity and with no cross-contamination observed. Based on the high catalyst activity and recyclability, a continuous flow process was developed which was applied for the efficient KR of 9 different alcohols and also utilized on a $28.8 \mathrm{mmol}$ scale. Current work is focused on using this new catalyst for other isothiourea-catalyzed reactions through application in batch and continuous flow processes. ${ }^{31}$

\section{ASSOCIATED CONTENT}

Supporting Information. Experimental procedures; characterization data for novel compounds; ${ }^{1} \mathrm{H}$ and ${ }^{13} \mathrm{C}$ NMR spectra and HPLC traces. This material is available free of charge via the Internet at http://pubs.acs.org.

\section{AUTHOR INFORMATION}

\section{Corresponding Author}

*mapericas@iciq.es (M.A.P.)

*gh23@st-andrews.ac.uk (G.H.)

*ads10@st-andrews.ac.uk (A.D.S.)

\section{Author Contributions}

All authors have given approval to the final version of the manuscript.

\section{ACKNOWLEDGMENT}

We thank the EPSRC Centre for Doctoral Training in Critical Resource Catalysis (CRITICAT, grant code EP/L016419/1, R.M.N.P.) for funding. Financial support from the EPSRC (EP/K000411/1) is gratefully acknowledged (R.C.). The European Research Council under the European Union's Seventh Framework Programme (FP7/2007-2013) ERC Grant Agreement No. 279850 is also acknowledged. A.D.S. thanks the Royal Society for a Wolfson Research Merit Award. We also thank the EPSRC UK National Mass Spectrometry Facility at Swansea University. C.R.E. and M.A.P. acknowledge the financial support from CERCA Programme/Generalitat de Catalunya, MINECO (CTQ201569136-R, AEI/MINECO/FEDER, UE and Severo Ochoa Excellence Accreditation 2014-2018, SEV-2013-0319) and DEC Generalitat de Catalunya (Grant 2014SGR827).

\section{REFERENCES}

(1) For reviews see: (a) Keith, J. M.; Larrow, J. F.; Jacobsen, E. N. Adv. Synth. Catal. 2001, 343, 5-26. (b) Vedejs, E.; Jure, M. Angew. Chem. Int. Ed. 2005, 44, 3974-4001. (c) Pellissier, H. Adv. Synth. Catal. 2011, 353, 1613-1666.

(2) Kagan, H. B.; Fiaud, J. C. Topics in Stereochemistry 1988, 18 , 249-330.

(3) For reviews see: (a) Murray, J. I.; Heckenast, Z.; Spivey, A. C. Chiral Lewis Base Activation of Acyl and Related Donors in Enantioselective Transformations ( $\rightarrow \pi^{*}$ ). In Lewis Base Catalysis in
Organic Synthesis; Vedejs, E., Denmark, S. E., Eds.; Wiley-VCH: Weinheim, 2016; Vol. 2, pp 459-526. (b) Muller, C. E.; Schreiner, P. R. Angew. Chem. Int. Ed. 2011, 50, 6012-6042.

(4) (a) Benaglia, M.; Puglisi, A.; Cozzi, F. Chem. Rev. 2003, 103, 3401-3429. (b) Trindade, A. F.; Gois, P. M. P.; Alfonso, C. A. M. Chem. Rev. 2009, 109, 418-514. (c) Lu, J.; Toy, P. H. Chem. Rev. 2009 , 109, 815-838.

(5) In addition, immobilized peptides and transition metal catalysts have been used for the KR of alcohols: (a) Copeland, G. T.; Miller, S. J. J. Am. Chem. Soc. 2001, 123, 6496-6502. (b) Gissibl, A.; Finn, M. G.; Reiser, O. Org. Lett. 2005, 7, 2325-2328. (c) Gissibl, A.; Padié, C.; Hager, M.; Jaroschik, F.; Rasappan, R.; Cuevas-Yañez, E.; Turrin, C.O.; Caminade, A.-M.; Majoral, J.-P.; Reiser, O. Org. Lett. 2007, 9, 2895-2898. (d) Schätz, A.; Hager, M.; Reiser, O. Adv. Funct. Mater. 2009, 19, 2109-2115. (e) Schätz, A.; Grass, R. N.; Kainz, Q.; Stark, W. J.; Reiser, O. Chem. Mater. 2010, 22, 305-310.

(6) Clapham, B.; Cho, C.-W.; Janda, K. D. J. Org. Chem. 2001, 66, 868-873.

(7) Pelotier, B.; Priem, G.; Campbell, I. B.; Macdonald, S. J. F.; Anson, M. S. Synlett, 2003, 5, 679-683

(8) (a) Ishihara, K.; Kosugi, Y.; Akakura, M. J. Am. Chem. Soc. 2004, 126, 12212-12213. (b) Kosugi, Y.; Akakura, M.; Ishihara, K. Tetrahedron 2007, 63, 6191-6203.

(9) Gleeson, O.; Tekoriute, R.; Gun'ko, Y. K.; Connon, S. J. Chem. Eur. J. 2009, 15, 5669-5673.

(10) In addition, the equivalents of anhydride and base were incrementally increased over the recycling process, indicating some catalyst degradation.

(11) For reviews on the use of solid-supported chiral catalysts in continuous flow processes see: (a) Puglisi, A.; Benaglia, M.; Chiroli, V. Green Chem. 2013, 15, 1790-1813. (b) Rodríguez-Escrich, C.; Pericàs, M. A. Eur. J. Org. Chem. 2015, 2015, 1173-1188. (c) Atodiresei, I.; Vila, C.; Rueping, M. ACS Catal. 2015, 5, 1972-1985.

(12) The KR of a 1,2-diol using a $\mathrm{Cu}(\mathrm{II})$-azabis(oxazoline) catalyst supported on a $\mathrm{Co} / \mathrm{C}$ nanoparticle has been reported in continuous flow, see ref $5 \mathrm{e}$. For the non-catalytic acylative parallel KR of amines in continuous flow see: Kreituss, I.; Bode, J. W. Nature Chem. 2017, 9, 446452.

(13) For a review see: Merad, J.; Pons, J.-M.; Chuzel, O.; Bressy, C.; Eur. J. Org. Chem. 2016, 2016, 5589-5610.

(14) Birman, V. B.; Li, X. Org. Lett. 2006, 8, 1351-1354.

(15) (a) Birman, V. B.; Guo, L. Org. Lett. 2006, 8, 4859-4861. (b) Birman, V. B.; Li, X. Org. Lett. 2008, 10, 1115-1118. (c) Zhang, Y.; Birman, V. B. Adv. Synth. Catal. 2009, 351, 2525-2529. (d) Xu, Q.; Zhou, H.; Geng, X.; Chen, P. Tetrahedron 2009, 65, 2232-2238. (e) Shiina, I.; Nakata, K.; Ono, K.; Sugimoto, M.; Sekiguchi, A.. Chem. Eur. J. 2010, 16, 167-172. (f) Shiina, I.; Ono, K.; Nakata, K. Chem. Lett. 2011, 40, 147-149. (g) Li, X.; Jiang, H.; Uffman, E. W.; Guo, L.; Zhang, Y.; Yang, X.; Birman, V. B. J. Org. Chem. 2012, 77, 17221737. (h) Nakata, K.; Gotoh, K.; Ono, K.; Futami, K.; Shiina, I. Org. Lett. 2013, 15, 1170-1173. (i) Shiina, I.; Ono, K.; Nakahara, T. Chem. Commun. 2013, 49, 10700-10702.

(16) (a) Belmessieri, D.; Joannesse, C.; Woods, P. A.; MacGregor, C.; Jones, C.; Campbell, C. D.; Johnston, C. P.; Duguet, N.; Concellón, C.; Bragg, R. A.; Smith, A. D. Org. Biomol. Chem. 2011, 9, 559-570. (b) Musolino, S. F.; Ojo, O. S.; Westwood, N. J.; Taylor J. E.; Smith A. D. Chem. Eur. J. 2016, 22, 18916-18922.

(17) (a) Izquierdo, J.; Pericàs, M. A. ACS Catal. 2016, 6, 348-356. (b) Wang, S.; Izquierdo, J.; Rodríguez-Escrich, C.; Pericàs, M. A. ACS Catal. 2017, 7, 2780-2785. (c) Wang, S.; Rodríguez-Escrich, C.; Pericàs, M. A. Angew. Chem. Int. Ed. 2017, 56, 15068-15072.

(18) (a) Joannesse, C.; Johnson, C. P.; Concellón, C.; Simal, C, Philp, D.; Smith, A. D. Angew. Chem. Int. Ed. 2009, 48, 8914-8918. (b) Belmessieri, D.; Morrill, L. C.; Simal, C.; Slawin, A. M. Z.; Smith, A. D. J. Am. Chem. Soc. 2011, 133, 2714-2720. (c) Maji, B.; Joannesse, C.; Nigst. T. A.; Smith, A. D.; Mayr, H. J. Org. Chem. 2011, 76, 5104 5112. (d) Robinson, E. R. T.; Fallan, C.; Smial, C.; Slawin, A. M. Z.; Smith, A. D. Chem. Sci. 2013, 4, 2193-2200. (e) Matviiksuk, A.; Greenhalgh, M. D.; Antúnez, D.-J. B.; Slawin, A. M. Z.; Smith, A. D. Angew. Chem. 2017, 129, 12450-12455. 
(19) Morrill, L. C.; Douglas, J.; Lebl, T.; Slawin, A. M. Z.; Fox D. J.; Smith A. D. Chem. Sci. 2013, 4, 4146-4155.

(20) For a review see: (a) Fernandez, A. E.; Jonas, A. M.; Riant, O. Tetrahedron 2014, 70, 1709-1731. For seminal reports see: (b) Rostovtsev, V. V.; Green, L. G.; Fokin, V. V.; Sharpless, K. B. Angew. Chem. Int. Ed. 2002, 41, 2596-2599. (c) Tornøe, C. W.; Christensen, C.; Meldal, M. J. Org. Chem. 2002, 67, 3057-3064.

(21) Bastero, A.; Font, D.; Pericàs, M. A. J. Org. Chem. 2007, 72, 2460-2468.

(22) See the Supporting Information for full details

(23) The absolute configuration of recovered alcohol was assigned as $(R)$ through comparison of its specific rotation with literature, see Supporting information for details.

(24) (a) Alfonsi, K.; Colberg, J.; Dunn, P. J.; Fevid, T.; Jennings, S.; Johnson, T. A.; Kleine, H. P.; Knight, C.; Nagy, M. A.; Perry, D. A.; Stefaniak, M. Green Chem. 2008, 10, 31-36. (b) Henderson, R. K.; Jiménez-González, C.; Constable, D. J. C.; Alston, S. R.; Inglis, G. G. A.; Fisher, G.; Sherwood, J.; Binks, S. P.; Curzona, A. D. Green Chem. 2011, 13, 854-862. (c) Prat, D.; Pardigon, O.; Flemmin, H.-W.; Letestu, S.; Ducandas, V.; Isnard, P.; Guntrum, E.; Senec, T.; Ruisseau, S.; Cruciani, P.; Hosek, P. Org. Process Res. Dev. 2013, 17, 1517-1525.

(25) The absolute configuration of recovered alcohol was assigned as $(1 R, 2 S)$ through comparison of its specific rotation with literature, see Supporting information for details.

(26) The absolute configuration of recovered alcohol was assigned as $(S, S)$ through comparison of its specific rotation with literature, see Supporting information for details.

(27) The selectivity factor for the KR of ( \pm )-45 was calculated using the er of isolated $(\boldsymbol{S}, \boldsymbol{S})-\mathbf{4 5}$, and the er of 'product', calculated by combining the ers of monoester $(\boldsymbol{R}, \boldsymbol{R}) \mathbf{- 4 6}$ and diester $(\boldsymbol{R}, \boldsymbol{R})-\mathbf{4 7}$, with their contributions weighted according to their ratio measured by ${ }^{1} \mathrm{H}$ NMR spectroscopy of the crude reaction product. If the contribution from the minor component of diester $(\boldsymbol{R}, \boldsymbol{R}) \mathbf{- 4 7}$ is omitted from the calculation an $s$ of 17 is obtained.

(28) For the isothiourea-catalyzed KR of a 1,3-diol see: (a) Merad, J.; Borkar, P.; Caijo, F.; Pons, J.-M.; Parrain, J.-L.; Chuzel, O.; Bressy, C. Angew. Chem. Int. Ed. 10.1002/anie.201709844. For the isothiourea-catalyzed desymmetrization of meso-diols see: (b) Birman, V. B.; Jiang, H.; Li, X. Org. Lett. 2007, 9, 3237-3240. (c) Merad, J.; Borkar, P.; Yenda, T. B.; Roux, C.; Pons, J.-M.; Parrain, J.-L.; Chuzel, O.; Bressy, C. Org. Lett. 2015, 17, 2118-2121.

(29) (a) Black, J. W.; Stephenson, J. S. Lancet 1962, 280, 311-314. (b) Howe, R. Nature 1965, 207, 594-595. (c) Howe, R.; Crowther, A. F.; Stephenson, J. S.; Rao, B. S.; Smith, L. H. J. Med. Chem. 1968, 11, 1000-1008.

(30) When using different alcohol substrates, $\mathrm{CHCl}_{3}$ was pumped at $0.1 \mathrm{~mL} \mathrm{~min}{ }^{-1}$ for $45 \mathrm{~min}$. When using different anhydrides, $\mathrm{CHCl}_{3} / \mathrm{MeOH}(9: 1)$ was pumped at $0.1 \mathrm{~mL} \mathrm{~min}^{-1}$ for $45 \mathrm{~min}$.

(31) The research data underpinning this publication can be found at DOI:

$$
\text { http://dx.doi.org/10.17630/5c945e1a-44ac-4c1a-8cb1- }
$$
a154bcefa4c6. 


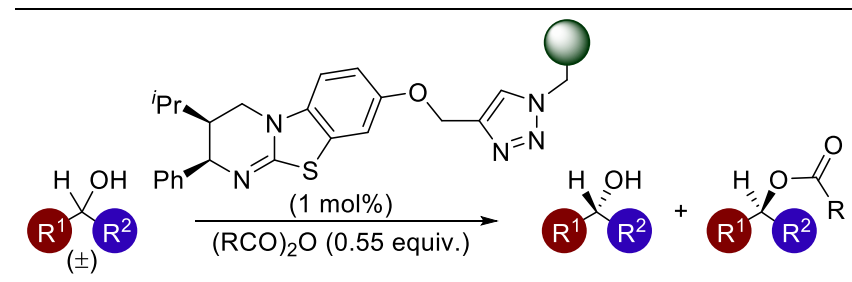

- 28 examples; -5 substrate classes (benzylic, allylic, propargylic, cycloalkanol, 1,2-diol); $\bullet s$ factors up to $>600$;

- Excellent catalyst recyclability; • Applied in continuous flow 